\title{
CENIZAS DE LA MEMORIA: \\ TESTIMONIO SOBRE CENSURAS, AUTOCENSURAS Y DESOBEDIENCIA
}

Jorge Montealegre 


\section{JORGE MONTEALEGRE}

Escritor y periodista. Doctor en Estudios Americanos de la Universidad de Santiago de Chile. Director del Departamento de Extensión, Vicerrectoría de Vinculación con el Medio, en la misma Universidad. Sus ámbitos de investigación son los estudios culturales, especialmente referidos al imaginario, la memoria y el humor gráfico. 


\section{CENIZAS DE LA MEMORIA: TESTIMONIO SOBRE CENSURAS, AUTOCENSURAS Y DESOBEDIENCIA}

"La memoria de las cenizas: de libros y editoriales quemados y censurados en dictadura", se llamó el panel de conversación en el marco de la conmemoración de los 40 años del golpe de Estado, organizado por el Observatorio del Libro y la Lectura de la Universidad de Chile. Ordeno los apuntes de mi testimonio y reordeno, para mis efectos, el título: de la memoria de las cenizas resultan cenizas de la memoria. Dispersas, volátiles, antes de que se las lleve el viento. Desde el fuego vuelan las pavesas. Son esas chispitas fugaces, débiles, que muy luego se apagan y caen convertidas en polvo. En cenizas, palabra evocadora de la muerte.

Es sabido que en todos los momentos históricos y en todas las civilizaciones se han eliminado libros. ${ }^{1}$ Chile no ha sido la excepción y no solo pasó 40 años atrás. En junio de 1844, hace 170 años, Francisco Bilbao fue procesado por su libro Sociabilidad chilena. No obstante haber sido absuelto del delito de sedición —relata Floridor Pérez-, se lo condenó "por inmoral y blasfemo" y la Corte Suprema ordenó que sus escritos fueran quemados (Pérez, 2014). Es decir, desde antes de ayer también llegan cenizas que no debemos olvidar; pero estas palabras, hilvanadas con mi testimonio personal, se limitarán al caso de la dictadura militar que se impuso el 11 de septiembre de 1973.

\section{SÍMBOLOS}

La Moneda en llamas es el primer ícono que anuncia el terrible lugar común: el derrocamiento del presidente Allende fue, literalmente, a sangre y fuego. Las cenizas señalaban que la revolución estaba hecha polvo. Desde entonces, la imagen del palacio incendiado — del fuego destructor - es un engrama que despierta evocaciones personales, con sus mitos y transferencias, que forman los diversos mosaicos que se mezclan en las memorias colectivas. La quema de La Moneda es significativa en sí como alegoría elocuente de la pérdida de la democracia, de las libertades y de la vía chilena al socialismo. Siniestro.

La bandera chamuscada en el frontis del palacio, el humo que la envuelve, es parte de la secuencia impresa en la memoria. Son símbolos sobre símbolos. Al interior, había otros que salvar del fuego. Y el presidente, con toda su investidura, se preocupa de ello. Así, en la magnitud de la situación cada uno de sus gestos es significativo y entre ellos está la silenciosa épica que hay tras el intento por salvar el Acta de Independencia: el

1. Al respecto, véase Báez, F., Nueva historia universal de la destrucción de libros. De las tablillas sumerias a la era digital, Barcelona: Ediciones Destino, 2011. 
documento se conservaba en una vitrina en el Salón Carrera que comenzó a incendiarse. Alguien rescata el Acta, lo entrega al Presidente de la República. Para salvar la reliquia Salvador Allende ordena que su secretaria - Miria Contreras, la Payita — se la llevara al salir del palacio y que "la entregara al primer soldado que encontrara, explicándole de qué documento se trataba". Lo hizo, pero el militar rompió el documento. ${ }^{2}$ Allende la salvó del incendio, evitó que el documento histórico se quemara en el palacio; pero los soldados, desde la obediente ignorancia, rompían y quemaban los papeles sospechosos.

\section{ANTORCHAS}

Con las cenizas de La Moneda se inicia el duelo, y la figura de Allende se convierte en una imagen proscrita. Peligrosa para quienes conservaran afiches, carátulas o libros con su rostro. Una imagen en la hoguera. Son innumerables los testimonios: "Yo era el único partidario de Allende en la casa y tuve que quemar todas mis cosas en el patio", ${ }^{3}$ cuenta el entonces adolescente Andrés Chadwick Piñera. "En ese momento en que quemé mis libros, quemé todo y borré una etapa", reflexiona años después entrevistado por Patricia Politzer. El joven derivó en partidario activo de la dictadura; con antorcha en la mano, fue uno de los 77 jóvenes distinguidos en el Acto de Chacarillas ${ }^{4}$ que juraron su apoyo a Pinochet.

Al respecto, valga una digresión. En la liturgia dictatorial el fuego devino un elemento distintivo desde sus inicios. Al celebrar el segundo aniversario del golpe, el 11 de septiembre de 1975, Augusto Pinochet encendió una "llama de la libertad" y ordenó levantar un "altar de la patria" donde debía estar el fuego perpetuo del auto-homenaje. La ceremonia se replicó en algunas provincias, con operativos masivos que comprometían a "la civilidad" que apoyaba al régimen.

Leo el folleto Chile 11 de septiembre de 1975, impreso en la Editora Nacional Gabriela Mistral (ex Quimantú). Algunos párrafos: "Llega el instante solemne en que un campesino, un trabajador urbano, un estudiante y una dueña de casa encienden las antorchas con el fuego que durante tres años guardó la civilidad en su corazón". "Invocamos una vez más a la Divina Providencia, para que ella nos guíe a encender la Llama de la

2. Cuenta Miguel Orellana, en cuya casa se refugió Miria Contreras, la secretaria del Presidente, días después del bombardeo de La Moneda: "A la Payita le confió el Acta de la Independencia, para salvarla de la destrucción. Le dijo que la entregara al primer soldado que encontrara, explicándole de qué documento se trataba. Fue su última decisión de Estado antes de suicidarse. Pero, según ella nos contó, los soldados no le hicieron caso y rompieron el viejo papel, firmado en Talca por el Director Supremo Bernardo O'Higgins Riquelme, un siglo y medio antes, en el primer aniversario de la Batalla de Chacabuco, el 12 de febrero de 1818", en Orellana Benado, M., Allende, alma en pena (una mirada libre), Santiago: Demens \& Sapiens, 1998, pág. 11.

3. Andrés Chadwick Piñera, entrevistado por Politzer, P., Miedo en Chile, Santiago: Cesoc, 1985, pág. 207.

4. El Acto de Chacarillas se realizó en 1977, detrás del cerro San Cristóbal. En la ocasión, Augusto Pinochet recibió el apoyo de jóvenes que se formaron con antorchas y banderas para saludar al dictador. Fueron representados por 77 elegidos, que simbolizaban a los 77 soldados caídos en la batalla de La Concepción, en la guerra con el Perú. 
Libertad, que iluminará por siempre los destinos de nuestra Patria. [...] Ahora os invito a todos a solidarizar con estos ideales, en una gran llamarada de Unidad Nacional, que exprese ante el mundo nuestra irrenunciable vocación por la libertad...". ${ }^{5}$ Ilustrado con fotografías de los actos, un pie de foto describe: "Centenares de miles de antorchas iluminan el cielo de Santiago al término de la ceremonia".

El fuego que había estado contenido "durante tres años" se desató y el terror indujo a que la propia población lo aplicara como una terrible — y a veces irracional— medida de autocensura. Al testimonio del joven Chadwick ("tuve que quemar todas mis cosas en el patio") habría que multiplicarlo por miles y, pertinentemente, considerar la bifurcación que nos propone el caso para distinguir lo que queda en el saber común (en las coincidencias que convergen en la memoria colectiva) y los destinos individuales.

\section{ALLANAMIENTOS}

La imagen de los militares quemando libros y otros impresos sacados, por ejemplo, de los allanamientos de las torres San Borja, fueron la notificación de que cada familia debía revisar lo que tenía en casa; había que asumir que tener ciertos libros, discos o afiches podía ser peligroso. Sobre esta noticia, que era un amedrentamiento generalizado, es simbólica la primera plana del diario El Mercurio del lunes 24 de septiembre de 1973. En ella, la noticia "falleció poeta Pablo Neruda" está en la parte inferior del diario. A su lado, una foto diez veces más grande que la del poeta muestra a los militares lanzando "propaganda marxista" a una fogata. Los militares quemaban bibliotecas y también lo hacían quienes temían sufrir un allanamiento. Algunos, junto con sentir la muerte de Neruda como un nuevo duelo debieron quemar al mismo tiempo sus libros.

Recurro a mi propio testimonio registrado en Frazadas del Estadio Nacional para referirme a los momentos de incertidumbre, en septiembre de 1973, de un eventual allanamiento:

"En la casa el peligro mayor era su biblioteca, los discos y las rumas de revistas y diarios de todas las tendencias. La idea de quemar libros pasó por mi cabeza, pero solo me llevaba a revisar cada libro y a pensar cómo esconderlo o a quién llevárselo. Ante la posibilidad de perderlos, me ponía a leer los libros. Nunca había leído tanto como en esos días.

Intenté, sí, quemar algunos títulos peligrosos y... ¡cómo me arrepentí entonces de haber respondido los cupones que ofrecían gratis los libros de Mao Tse Tung y de Kim Il Sung! Llegaron por toneladas a la casilla de correos. En ediciones de lujo y rústicas. En papel couché y en papel de arroz. Paradójicamente, no podía quemar los encendidos Escritos militares. Sus tapas plásticas ardían lentamente, produciendo un humo negro que podía atraer no solo a los milicos, sino también a los bomberos. Intenté salvar algunos llevándolos a otras casas. No siempre me aceptaban el regalo.

5. Chile 11 de septiembre de 1975, folleto impreso en Editora Nacional Gabriela Mistral. 
Tenían suficiente enterrando o prendiéndole fuego a los propios. Los militares quemaban libros. Nosotros también. Era una locura" (pág. 29).

Efectivamente allanaron mi casa. Era un remolino. Los soldados revisaron todo. No encontraron armas, por supuesto. Sí muchos libros y discos que se llevaron. Lo peor fue que encontraron mi carnet de militante:

"¿Cómo destruir el carnet del Partido, que tanto había deseado recibir? No me atreví a quemarlo. Como otros recuerdos, lo quise conservar. Por sentimentalismo, por cariño. Fetichista o cachurero, para mí siempre ha sido difícil cumplir toda instrucción que signifique deshacerme de papeles y recuerdos. Así es que lo escondí en un grueso y antiguo diccionario" (pág. 25).

"Me llevaron a la Escuela Militar: Desde el lugar en que me tuvieron hincado por horas pude observar mi entorno y ver cómo se quemaban en los patios de la Escuela revistas, libros, discos. Muchos papeles. Seguramente en esa hoguera ardía lo que habían sacado de mi casa".

Si pertenecer a un partido político devino ilegal, era la democracia lo que desaparecía y sus expresiones que permitían la vía electoral, el sufragio. Por ello es un símbolo elocuente la quema los registros electorales.

Quemar los vestigios de la Unidad Popular fue urgente para la dictadura. Y quemar era sinónimo de borrar, eliminar, hacer desaparecer. Destruir. ¿Cuáles — junto a las personas- eran los signos más evidentes y susceptibles de sospecha? Además de las publicaciones y títulos evidentemente "marxistas", la sola posesión de libros que tuvieran el logotipo de la Editora Nacional Quimantú hacía del lector un sospechoso de extremismo. De hecho, el 15 de septiembre de 1973, Quimantú fue allanada por un contingente militar que destruyó en las guillotinas miles de ejemplares de libros. Es sabido que muchos ejemplares fueron quemados, pero que también fueron escondidos en entretechos o enterrados en patios y parcelas.

\section{SEÑAS DE IDENTIDAD}

Otra forma de eliminación fue el cambio de nombres de lugares e instituciones. La misma Quimantú ("sol del saber", en mapudungun) es un buen ejemplo: supuestamente, la connotación upelienta e indígena de la denominación se relegaba al olvido con el nuevo nombre de la Editora Nacional como Gabriela Mistral, demostrando entonces una gran ignorancia sobre el pensamiento y obra de la poeta: "Sabe usted que no creo en la mano militar para cosa alguna. [...] Ni el escritor, ni el artista, ni el sabio, ni el estudiante pueden cumplir su misión de ensanchar las fronteras del espíritu si sobre ellos pesa la amenaza de las Fuerzas Armadas, del Estado gendarme que pretende dirigirlos". ${ }^{6}$

6. Gabriela Mistral, en carta a Benjamín Carrión (1897-1979), escritor y político ecuatoriano. 
También es elocuente la inmediata eliminación de la figura de Violeta Parra. A la población Violeta Parra de Concepción le cambiaron nombre de inmediato y pasó a llamarse Luis Cruz Martínez, subteniente, héroe de la batalla de La Concepción. Según se dijo oficialmente e informó El Mercurio, el cambio se hizo "como una manera de hacer justicia a los valores propiamente nacionales y poner término a las designaciones políticas". ${ }^{7}$ Por otra parte, la estación de Metro que ya tenía asignado el nombre Violeta Parra, al inaugurarse apareció como Neptuno.

La artista múltiple nos permite recordar también la quema de discos "peligrosos" o, en la autocensura, su enmascaramiento con forros y carátulas de otros discos "inocentes". Las grabaciones originales de la Cantata Popular Santa María de Iquique fueron quemadas. 40 años después apareció accidentalmente una de ellas. También se destruyó, entre otros, el disco Payo Grondona en serio. ¿Qué libro, qué disco quemar u ocultar? ¿Qué adorno de la casa podría ser sospechoso o alentar la delación de algún vecino? ¿Cómo vestirse, cómo llevar el pelo?

"En una esquina los soldados me detienen y amenazan con cortarme el pelo con una bayoneta. Prometí que me lo cortaría ese mismo día para que me soltaran. El pelo largo, de hippie o guerrillero, para los milicos era un síntoma de indisciplina, desorden y relajo moral. Había que cortarlo violentamente. Algunos lolos no tuvieron mi suerte y fueron rapados en la calle de manera humillante. Era peligroso seguir siendo la misma persona. Como por instinto, la autocensura comenzó por el propio cuerpo y quienes tuvieron que cortarse la barba andaban doblemente pálidos" (pág. 24).

A las mujeres les rajaron los pantalones, a otros les rompieron con bayonetas sus boinas "guevaristas". En la memoria está la prohibición de los instrumentos de música andina: quenas y charangos de golpe estuvieron proscritos. Para no creer. Y la adorable Mafalda también fue prohibida. Otro elemento a borrar fueron las consignas y gráficas de las brigadas muralistas, en las que colaboraban artistas como Roberto Matta y Guillermo Núñez, y cubrir los coloridos y característicos carteles de la UP, muchos de ellos firmados por Vicho + Toño Larrea. Para ello, la dictadura organizó la llamada "operación limpieza", en que se utilizaron estudiantes para blanquear las paredes y eliminar todo lo que recordara al gobierno de Allende.

Las más básicas señas de identidad fueron violentadas, vigiladas con un apremio que inducía la autocensura. Si el cuerpo y la indumentaria eran significativas y susceptibles de la propia autocensura, también la voz podía ser riesgosa: cualquiera con acento centroamericano podía ser cubano —y, por ende, guerrillero-, así como a todo uruguayo se le podía atribuir militancia tupamara (en el Estadio Nacional, un uruguayo simuló ser una persona sordomuda para no revelar su acento peligroso). Había que ocultar los signos que indicaban la pertenencia a una misma comunidad, que contaba con un vigoroso acervo

7. El Mercurio, Santiago, 2 de octubre de 1973, en Montealegre, J., Violeta Parra. Instantes fecundos, visiones, retazos de memoria, Santiago: Editorial USACH, 2011, pág. 76. 
sociocultural compartido, ${ }^{8}$ que en nuestro caso incluía fuertes tradiciones enraizadas en el movimiento popular.

Nos quedaban los guiños, delatores de un sistema simbólico compartido de visiones del mundo y del ser humano, de los valores y los "gustos" o preferencias estéticas, vinculadas a una sensibilidad de época. El libro, el disco, los afiches, la ropa se vinculaba con el acervo que deja lo vivido, lo visto y leído al interior de una ciudadanía que compartía convicciones políticas, subjetividades, mitos, símbolos y un cierto orden moral compartido, fundado en los valores que promovía la izquierda latinoamericana de entonces. La identidad compartida fue violentada. La intimidad de las cartas también fue violada por los censores y, en Chacabuco, un oficial ordenó la quema de cientos de cartas que eran esperadas con ansiedad por sus destinatarios. Así, ciertas lecturas y audiciones se convirtieron en placeres clandestinos. Más adelante, en 1977, el teatro también fue víctima del fuego censor cuando, durante el toque de queda, fue incendiada la carpa donde se representaba la obra Hojas de Parra, de don Nicanor. El mismo año, el Ministerio del Interior prohibió la importación de las novelas de Gabriel García Márquez, Mario Vargas Llosa y Julio Cortázar, por los reiterados ataques que estos escritores hacen a la dictadura militar.

\section{OCULTAMIENTOS}

Cuando allanaron mi casa lo que más nos inculpaba era la biblioteca. El marxismo, ensayo antimarxista, fue motivo de zamarreo; y La revolución de las células, texto de biología, fue un título sospechoso. En otras casas, El cubismo invocó a Fidel Castro. Hay otras anécdotas tragicómicas, pero reducir la destrucción de libros a la reacción solamente de "milicos ignorantes" sería subestimar el objetivo trascendente orientado a destruir todo vestigio de un momento histórico de conquistas populares (no hay que perdonarlos, porque sabían lo que hacían). La quema de libros no es solamente la destrucción de volúmenes materiales, la dimensión física de la publicación, sino que es un atentado a la memoria. Por ello, no debían quedar huellas. Por ello, después de los libros del primer momento, la misión sería destruir los vestigios de los propios crímenes de la dictadura.

Ilustrativa de esta política es la destrucción de los hornos de Lonquén, que fueron volados con dinamita, así como la llamada "operación retiro de televisores", que fueron maniobras planificadas de encubrimiento mediante la destrucción de lugares y la remoción de las fosas clandestinas donde se había arrojado a víctimas desaparecidas. El extremo en este contexto es el ataque con fuego contra las personas. Lo testimonia la quema intencionada de la estudiante Carmen Gloria Quintana, que resultó desfigurada; y Rodrigo Rojas Denegri, joven fotógrafo que murió dos días más tarde a consecuencia de las quemaduras. Ambos fueron quemados por una patrulla militar, el 2 de julio de 1986. El aserto de Heinrich Heine, "allí donde queman libros, acaban quemando hombres", resultó dramáticamente pertinente. En El Mercurio, cuenta un testigo de la escena,

8. Mayor reflexión sobre el "acervo sociocultural compartido" en Montealegre, J., Memorias eclipsadas. Duelo y resiliencia comunitaria en la prisión política, Santiago: Asterión, 2011. 
Agustín Edwards se indignó al ver la página con la noticia. "No quiero chicharrones en mi diario", habría sido su grito de censura.

\section{DESOBEDIENCIA}

A pesar de todo, de la quema de libros, del duelo, del terrorismo de Estado, desde el primer momento hubo gestos de desobediencia en el ámbito del salvataje de la palabra; muchos de ellos en los campos de prisioneros. Uno de los más simbólicos ha sido la escritura y rescate de los últimos versos de Víctor Jara, escritos en el Estadio Chile una hora antes de que fuera asesinado. El escrito, cuenta Boris Navia, se fue al Estadio Nacional en su libreta:

"Acordamos guardar este poema. Un zapatero abrió la suela de mi zapato y allí escondió las dos hojas del poema. Antes, yo hice dos copias de él, y junto al ex senador Ernesto Araneda, también preso, se las entregamos a un estudiante y a un médico que saldrían en libertad. Sin embargo, el joven fue chequeado por los militares en la puerta de salida y le descubrieron los versos de Víctor. Lo regresaron, y bajo tortura obtuvieron el origen del poema. Llegan a mí y me llevaron al velódromo, transformado en recinto de torturas e interrogatorio. [...] El oficial me ordena sacarme el zapato donde oculto los versos. ¡Ese zapato, cabrón!, grita. Su brutalidad se me viene encima. Golpeó el zapato hasta hacer salir las hojas escritas". ${ }^{9}$

El poema se salvó. Y otros se escribieron en el Estadio Nacional —Rafael Salas y Luis Vitale, entre otros autores_- y en Chacabuco hubo "festivales" de la canción y la poesía, con jurados competentes, diplomas y premios en consonancia con la precariedad de la situación. Sobre esto, en los años 80, fui entrevistado por el diario Fortín Mapocho. La entrevista se publicó, pero justamente en esos días imperaba el ridículo Bando 19, que prohibía la publicación de "todo tipo de imágenes". Por tanto, mi fotografía se convirtió en un recuadro gris con la mención del Bando encima: censurada, como todas las otras de ese diario. Aquella medida absurda fue combatida con creatividad y humor. El dibujante de la viñeta editorial del Fortín — la "Margarita" de Gustavo Donoso— propuso un juego interactivo que consistía en que el lector, uniendo los números dados, hiciera él mismo el dibujo editorial que consistía en un jeroglífico que — con la imagen de una vaca y algunas letras — formaba la consigna "va a caer".

La organización de los presos políticos, al menos en Chacabuco, contemplaba la autocensura como una medida de autocuidado. Hay un documento que revela el grado de organización de los prisioneros y la política de autocensura que se imponía para mantener los permisos obtenidos. Se trata del cuaderno en que el Presidente del Consejo

9. Navia, B., "Tareas sobre la marcha. Testimonio sobre la muerte de Víctor Jara", en http://biblioteca. clacso.edu.ar/subida/Panama/cela/20120717040228/testimonio.pdf. Sitio revisado en mayo de 2014. 
de Ancianos $^{10}$ apuntaba los asuntos que se trataban en las reuniones. Entre los temas planteados están: "Criterios para limitar la expresión de teatro y, en general, artística", "Criterio para charlas", "Qué mecanismos de censura se pueden establecer".

\section{EMPRESAS DE PAPEL}

La estela dejada por los prisioneros y en el ámbito literario tiene manifestaciones materiales en su mismo código: "libros", "editoriales" y "bibliotecas". En efecto, en el juego social de imitación de la realidad deseada, en Chacabuco se "editaron libros". El editor fue el poeta Rafael Eugenio Salas. Armado con un lápiz pasta, papel calco y un poco de alambre, Salas publicó artesanalmente —bajo el sello Jores Monsal— dos volúmenes de una "colección" que quedó inconclusa: el primer libro fue una selección del Canto a mí mismo, de Walt Whitman, traducido por León Felipe (marzo, 1974); y el segundo es una autoedición: Décimas del recuerdo (abril, 1974), escritas por el mismo poeta Salas, con ilustraciones de Héctor Morales. Tuvo un tiraje de solo dos ejemplares. El pequeño libro, de 32 páginas, "encuadernado" con un corchete de alambre, es un vestigio simultáneamente del trabajo artesanal, de la presencia de la música, del dibujo y la poesía. Y también de arte escénico. El mismo autor se recuerda en la función: "Actué y dirigí mi propio poema teatralizado Las Décimas del Recuerdo que, como lo he señalado en otras ocasiones, es un buen poema, pero una pésima obra de teatro". Las Ediciones Jores Monsal tuvieron una versión clandestina fuera del campo de prisioneros. Mi hermano Oscar (1952-2014), quien fue un héroe silencioso, con una máquina fiscal transcribió los poemas de Chacabuco y los editó, con copias hechas con papel calco y hojas muy delgadas, "papel cebolla", con el cual se podían hacer hasta cinco copias legibles.

Desde lejos, los "poetícolas" (como diría Armando Uribe) nos hacíamos señales de humo con revistas. Literatura chilena en el exilio, Araucaria, Canto Libre, tantas otras... En París me embarqué en un Barco de papel y, en 1979, me vine con él a Chile. Ya habíamos hechos cinco números y aquí no tenía otra posibilidad que ser un barco clandestino. Hicimos tres números más: dos "printed in Chile". Uno de ellos impreso a mimeógrafo en la misma casa, con harto susto y la radio a todo volumen para apagar el ruido de la imprenta; otro, en un offset increíble, que seguirá anónima mientras su operario no pueda recibir su debido homenaje. El tercero quedó inédito.

Del Barco de papel pasé, junto a otros amigos, a La Castaña, que nunca la pensamos como una revista clandestina. Para ello, había que someter los originales a la censura previa. La dictadura tenía la facultad de restringir la libertad de información y de autorizar o no la fundación, edición o circulación de nuevas publicaciones. En mi caso, participé en

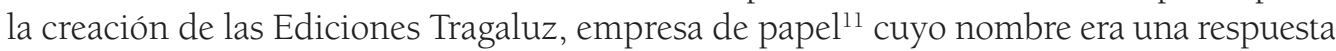

10. Este cuaderno se encuentra en el Museo de la Memoria y los Derechos Humanos. Donación de Mariano Requena, quien fue presidente del Consejo de Ancianos en el campo de prisioneros de Chacabuco, 1974.

11. Les llamábamos irónicamente "empresas de papel", parodiando a las empresas que estaban proliferando en la economía chilena fruto de la especulación financiera. 
modesta al oscurantismo del llamado "apagón cultural". Como no era legal, hice como persona natural el trámite de solicitar permiso para publicar la revista La Castaña (humor, gráfica y poesía). Nunca tuvimos respuesta. Ese era el sistema: no había plazo para que el gobierno tomara una decisión y la comunicara: simplemente no respondía (lo que era una respuesta) en lugar de negar explícitamente la autorización. La Castaña la publicamos sin la autorización y circuló de mano en mano y de mesa en mesa gracias al trabajo de Erwin Díaz. La sacamos igual desde 1981 hasta 1987, publicando ocho números de esa revista. Quisimos sacar cuatro números al año, pero fuimos de una rigurosa irregularidad. El último también quedó inédito.

En los 80, años de mayor institucionalización de los estados de excepción (que ya no eran excepcionales), los funcionarios de gobierno hacían esfuerzos por negar lo evidente y explicar la censura. Para Enrique Campos Menéndez, escritor que fue asesor de la Junta militar, Director de la DIBAM y recompensado con el Premio Nacional de Literatura:

"La censura no existe para quien escriba libremente, con el propósito de ilustrar el pensamiento honrado acerca del escritor. Existe, en cambio para aquellos que utilizan el medio literario para fines que nada tienen que ver con la verdad y la belleza, sino con compromisos ajenos a la íntima expresión del escritor. La censura existe también para aquellos que quieren salirse de una armónica convivencia de progreso y de paz, y que aprovechan el medio más noble de expresión humana, que es la literatura, para fines ajenos y hasta antagónicos a ella, como son la violencia y la subversión". ${ }^{12}$

\section{FOGATA Y ENTIERRO}

Por último, me permito contar una última anécdota que concentra varios de los elementos mencionados. Una pequeña historia de exilio y retorno, de nostalgias, miedos y (auto)censuras.

Hay una felicidad que nunca tuve. Aquella de retirar tu primer libro de la imprenta y sentir el olor a tinta de la creatura. Mi primer libro de poemas se llama Huiros (originalmente quise llamarlo Tierra de hojas, pero Armando Uribe estimaba que dos palabras eran mejor que tres y una mejor que dos para un título; en esos días Uribe fue mi maestro y yo, afortunadamente, seguí gran parte de sus consejos). El libro lo imprimió Marcel Young, en un taller de la Rue de Vaugirard, a mimeógrafo. El diseño (formato y diagramación) fue una idea de Guillermo Núñez, en base a un corte del típico papel roneo. Yo piqué cada esténcil pocas horas antes de volver a Chile y lo dejé listo para ser impreso. Era agosto de 1979. Volví sin asistir al parto. No supe cuándo fue ni cuántos ejemplares se tiraron. Tampoco tuve un ejemplar propio: enviarlo por correo era peligroso.

Años más tarde me conseguí uno que le había llegado a un amigo. Para la celebración de un aniversario partidario se hizo un acto clandestino en el local de una vicaría.

12. El Mercurio, suplemento Artes y Letras, 14 de junio de 1981, pág. E9. 
Antes de los discursos políticos, con Sergio González leímos algunos poemas. Nos turnábamos, uno y uno. Yo estaba leyendo muy concentrado cuando Sergio me hace señas para que me calle. Yo, seguía leyendo. Me tironeó hasta que guardé silencio. ¿Estábamos leyendo demasiado? No era eso: habían llegado los carabineros. Tenían rodeado el lugar y nadie podía salir del recinto. El pánico se apoderó de muchos y comenzaron a aparecer agendas con direcciones y documentos comprometedores. En el patio, entonces, se quemaron algunos papeles. Yo tenía mi libro, editado por la IC y con mi nombre en la portada. Así que le saqué la tapa, la rompí y la eché al fuego. El resto del libro no quise quemarlo. Como tampoco era prudente que lo retuviera, lo enterramos en el jardín de la vicaría. Y nunca volví a buscarlo. Si hubiese sospechado su destino, seguramente habría vuelto a su título original: Tierra de hojas, un país de papel, en el exilio; un libro de tierra, en el regreso.

Finalmente, me doy cuenta que tanto mi salida de Chile como mi regreso tuvieron la marca del fuego y de la censura.

\section{BIBLIOGRAFÍA}

Báez, F., Nueva historia universal de la destrucción de libros. De las tablillas sumerias a la era digital, Barcelona: Ediciones Destino, 2011.

Montealegre, J., Frazadas del Estadio Nacional, Santiago: LOM, 2003.

—-Violeta Parra. Instantes fecundos, visiones, retazos de memoria, Santiago: USACH, 2011.

-Memorias eclipsadas. Duelo y resiliencia comunitaria en la prisión politica, Santiago: Asterión, 2011.

Navia, B., "Tareas sobre la marcha. Testimonio sobre la muerte de Víctor Jara", en http://biblioteca. clacso.edu.ar/subida/Panama/cela/20120717040228/testimonio.pdf. Sitio revisado en mayo de 2014.

Orellana Benado, M., Allende, alma en pena (una mirada libre), Santiago: Demens \& Sapiens, 1998.

Pérez, F., Efemérides nacionales comentadas, Santiago: Zig-Zag, 2014.

Politzer, P., Miedo en Chile, Santiago: Cesoc, 1985. 